\title{
Bifunctional FePt Core-Shell and Hollow Spheres: Sonochemical Preparation and Self-Assembly
}

\author{
Junzhong Wang, ${ }^{\dagger}$ Kian Ping Loh, ${ }^{\dagger *}$ Yu Lin Zhong, ${ }^{\dagger}$ Ming Lin, ${ }^{\star}$ Jun Ding, ${ }^{\#}$ Yong \\ Lim Foo
}

${ }^{\dagger}$ Department of Chemistry, National University of Singapore, 3 Science Drive 3, Singapore 117543,

\# Department of Materials Science \& Engineering, National University of Singapore, Singapore 119620,

$\ddagger$ Institute of Material Research and Engineering, 3 Research Link, Singapore 117602.

Email: chmlohkp@nus.edu.sg 

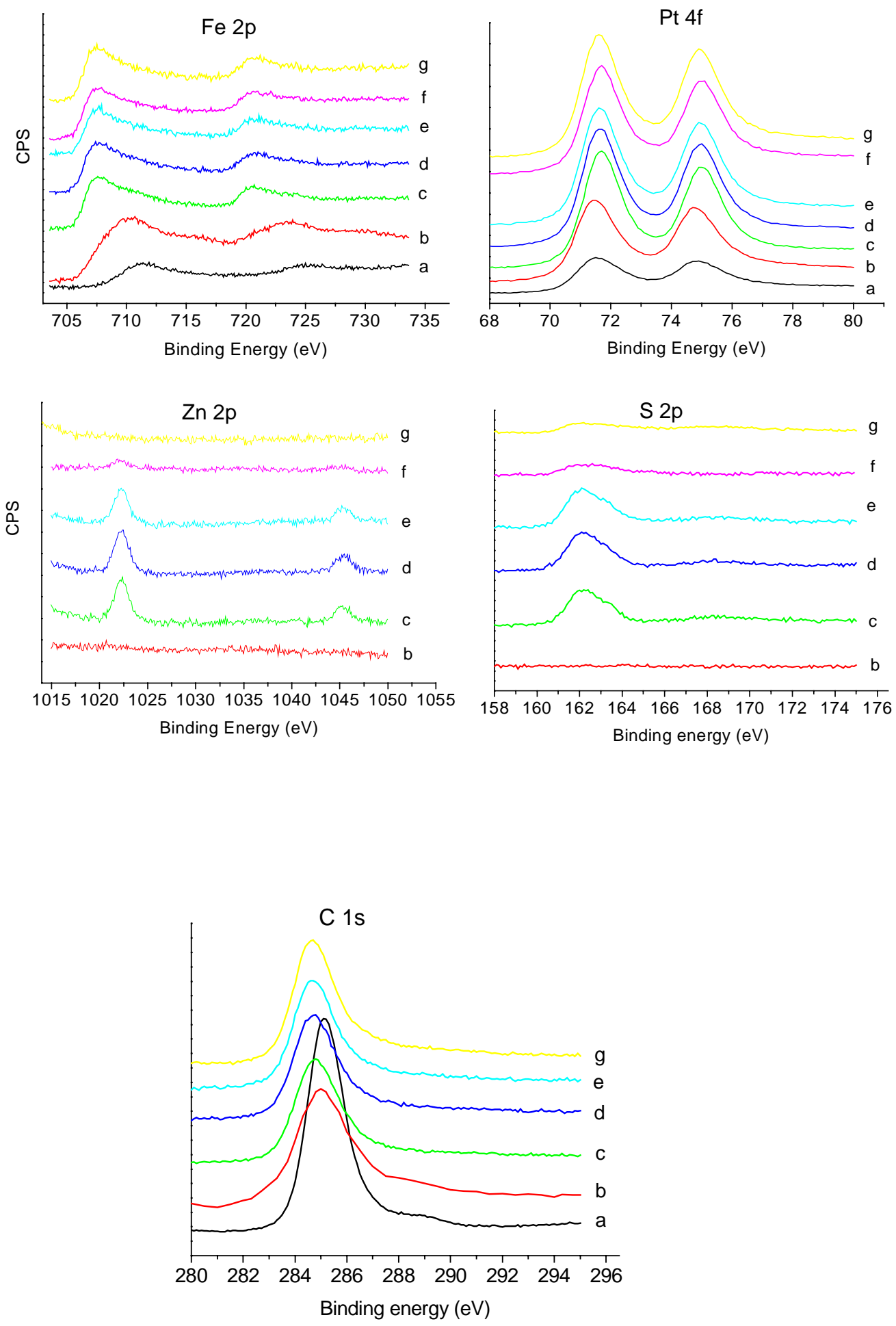
Figure S1. XPS data of $\mathrm{FePt} / \mathrm{ZnS} / \mathrm{SiO}_{2}$ annealed under high vacuum at various temperatures (a) $25^{\circ} \mathrm{C}$, (b) $200^{\circ} \mathrm{C}$, (c) $300^{\circ} \mathrm{C}$, (d) $400^{\circ} \mathrm{C}$, (e) $500^{\circ} \mathrm{C}$, (f) $530^{\circ} \mathrm{C}$, (g) $590^{\circ} \mathrm{C}$

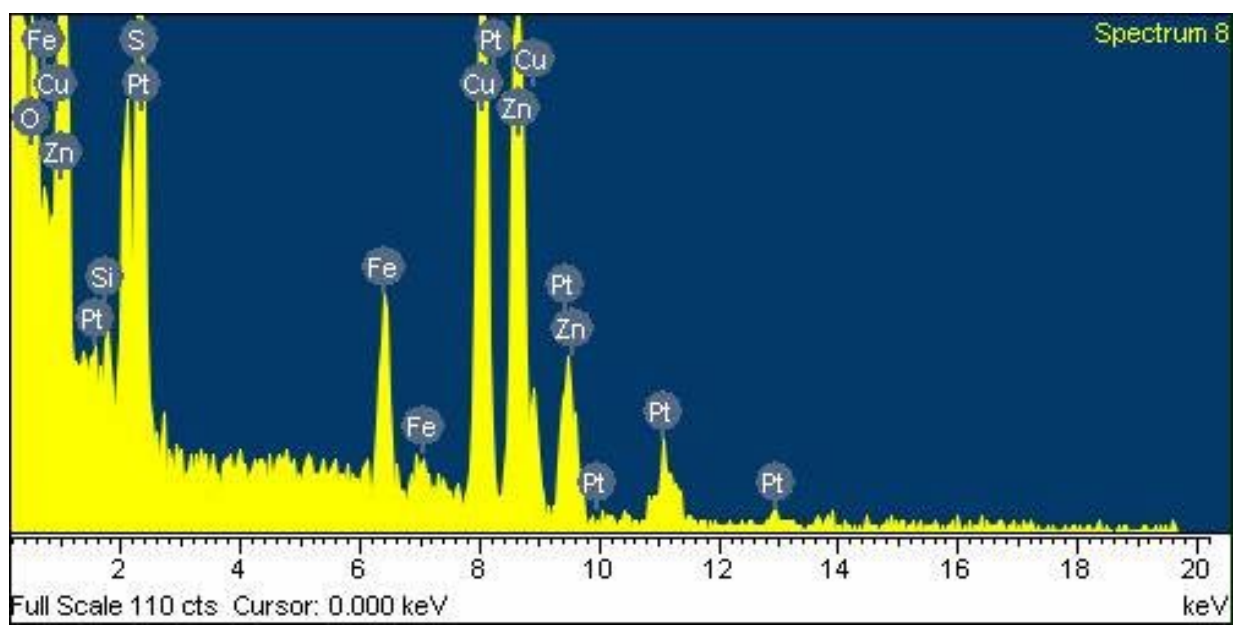

Figure S2. EDX data of sonochemically-prepared $\mathrm{FePt} / \mathrm{ZnS} / \mathrm{SiO}_{2}$ (The composition of the sample is Fe 5.6\%, Pt 6.2\%, Zn 41.5, S 46.7\% (atm\%)).

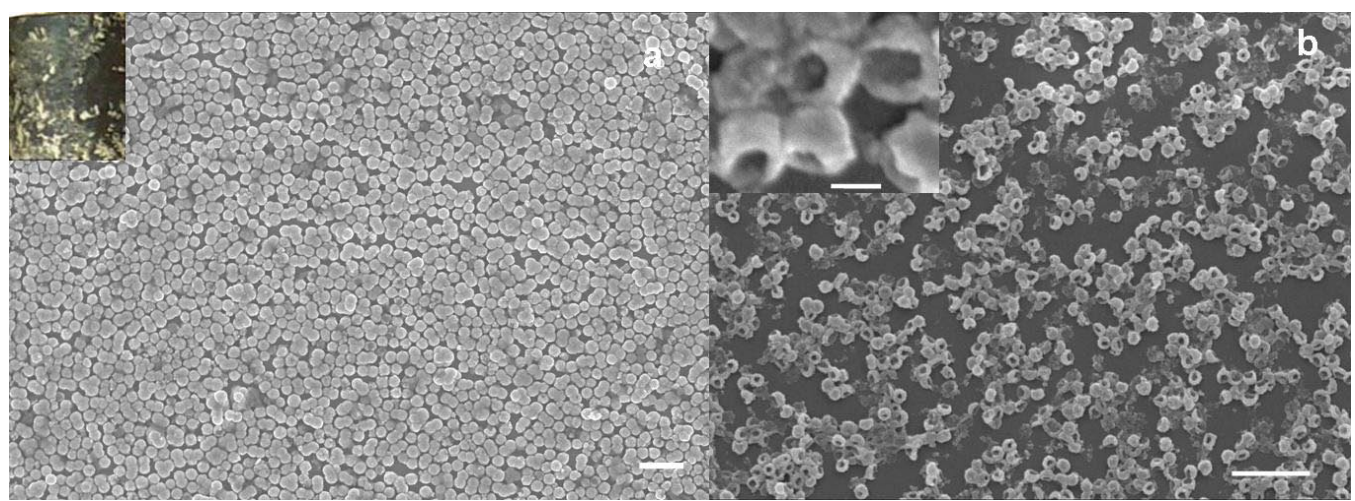


Figure S3. SEM images of self-assembly quasi-monolayer on Si substrate: (a) $\mathrm{FePt} / \mathrm{ZnS} / \mathrm{SiO}_{2}$, green reflection (inset in the left above: photograph of samples $(\sim 5 \times 8$ $\mathrm{mm})$ scattered in the $\{111\}$ planes), (b) hollow FePt (inset the magnified image) without annealing (The bar is $1 \mu \mathrm{m}$ and the inset bar is $200 \mathrm{~nm}$ ).

Quasi-monolayers can present different color reflections in the $\{111\}$ planes $\left(45^{\circ}\right)$, which is related to the inter-distance of self-assembled particles (green reflection is shown in the inset in Figure S3a). When interparticle spacing become larger, the reflected light red-shifted from purple to green color, which is consistent with the Bragg diffraction equation, $2 d \sin \theta=m \lambda$, where $d$ is the spacing between (111) planes and $m$ is the diffraction order. ${ }^{29}$ Hollow FePt sphere self-assembly is shown in Figure S3b. 